\title{
Can Endoscopic Ulcerations in Early Gastric Cancer Be Clearly Defined before Endoscopic Resection? A Survey among Endoscopists
}

\author{
Sung Min Park, Byung-Wook Kim, Joon Sung Kim, Young Wook Kim, Gi Jun Kim and Seung Ji Ryu \\ Division of Gastroenterology, Department of Internal Medicine, Incheon St. Mary's Hospital, College of Medicine, The Catholic University of \\ Korea, Incheon, Korea
}

Background/Aims: Early gastric cancer (EGC) with ulcerations can be treated via endoscopic resection (ER) when it is differentiated pathologically, limited to the mucosa, and $<3 \mathrm{~cm}$ in diameter. The presence of ulceration is a key factor in deciding treatment strategies and is usually diagnosed during endoscopic examination. The aim of this study was to evaluate whether ulcerations in EGC can be clearly defined among endoscopists and which factors are related to the differences.

Methods: A survey questionnaire, composed of demographic features and endoscopic images of seven patients with EGC, was presented to the endoscopists via e-mail. The endoscopists were asked whether such patients have ulcerations in the lesions.

Results: The questionnaires were e-mailed to 197 endoscopists, and 103 doctors replied. The presence of an endoscopic ulceration was defined differently among the endoscopists, depending on the duration of endoscopic practice and the experience of endoscopic submucosal dissection. The differences were especially high in the lesions without mucosal breaks and converging folds, which were expected to be viewed as non-ulcerative.

Conclusions: Before ER, endoscopic ulcerations in EGC must be reviewed by experienced endoscopists to reduce overestimations, and adequate educational programs for trainees should be established. Clin Endosc 2017;50:473-478

Key Words: Stomach neoplasms; Endoscopic resection; Ulcer; Surveys and questionnaires

\section{INTRODUCTION}

Early gastric cancer (EGC) is defined as cancer cells limited to the mucosa or submucosa, irrespective of lymph node metastasis. ${ }^{1,2}$ Endoscopic resection (ER) has been widely performed for the treatment of EGC with a very low possibility of lymph node metastasis. ${ }^{3-5}$ According to the Japanese Guidelines for Gastric Cancer, ${ }^{6}$ the following four factors should be defined to determine ER as a treatment modality: size, depth

Received: October 24, 2016 Revised: February 27, 2017

Accepted: March 2, 2017

Correspondence: Byung-Wook Kim

Division of Gastroenterology, Department of Internal Medicine, Incheon St. Mary's Hospital, College of Medicine, The Catholic University of Korea, 56 Dongsu-ro, Bupyeong-gu, Incheon 21431, Korea

Tel: +82-32-280-5052, Fax: +82-32-280-5987, E-mail: gastro@catholic.ac.kr

(cc) This is an Open Access article distributed under the terms of the Creative Commons Attribution Non-Commercial License (http://creativecommons.org/ licenses/by-nc/3.0) which permits unrestricted non-commercial use, distribution, and reproduction in any medium, provided the original work is properly cited. of invasion, pathological differentiation, and presence of ulceration. The size can be measured easily during endoscopic examination, and differentiation is usually determined by pathologists. The depth of invasion is usually determined by performing naked-eye assessment and/or via endoscopic ultrasound.

Gotoda et al. suggested the indication of ER for EGC after vigorous investigation of surgical specimens. ${ }^{5}$ In this study, the ulceration, or ulcer scar, was defined as converging folds, deformity of the muscularis propria, or fibrosis in the submucosa, or the deeper layers. However, ulcerations in EGC should be determined based on the endoscopic findings in the clinical practice, since misinterpretation of endoscopic ulcerations might result in a more aggressive treatment. We conducted this survey to determine whether ulcerations in EGC can be clearly defined among endoscopists and which factors are related to the differences. 

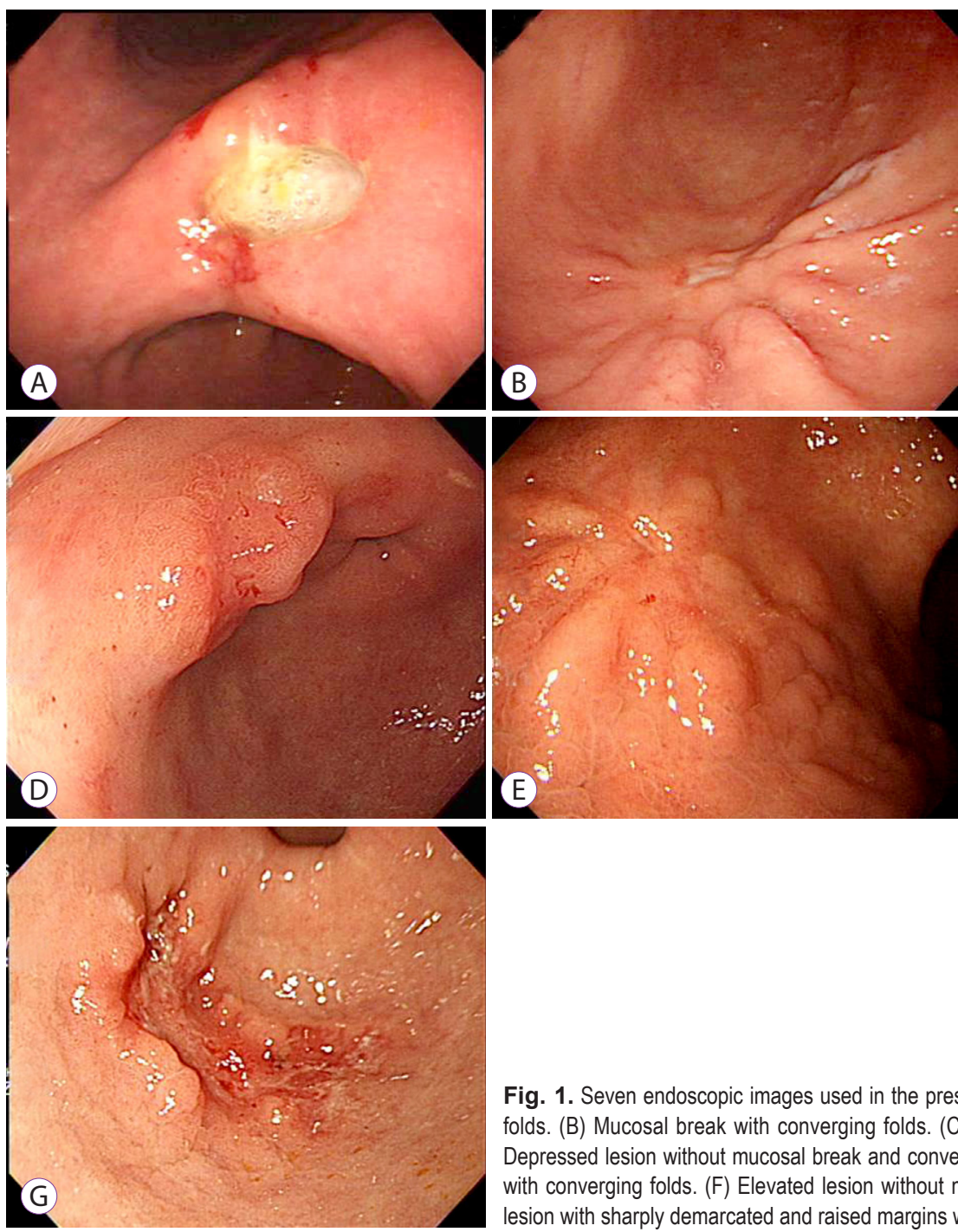

Fig. 1. Seven endoscopic images used in the present survey. (A) Deep mucosal break without converging folds. (B) Mucosal break with converging folds. (C) Shallow mucosal break without converging folds. (D) Depressed lesion without mucosal break and converging folds. (E) Depressed lesion without mucosal break with converging folds. (F) Elevated lesion without mucosal break and converging folds and (G) Depressed lesion with sharply demarcated and raised margins with mucosal break and no converging folds.

\section{MATERIALS AND METHODS}

\section{Survey method}

Survey questionnaires composed of a brief summary of each case and endoscopic images of seven patients with EGC (Fig. 1) were presented to the endoscopists via e-mail. They responded via e-mail with their demographic features, including age, sex, medical board status, position, duration of endoscopic experience, and experience of endoscopic submucosal dissection (ESD). Each endoscopic image represented the following features: (A) Deep mucosal break without converging folds; (B) Mucosal break with converging folds; (C) Shallow mucosal break without converging folds; (D) Depressed lesion without mucosal break and converging folds; (E) Depressed lesion without mucosal break with converging folds; (F) Elevated lesion without mucosal break and converging folds; and (G) Depressed lesion with sharply demarcated and raised margins with mucosal break and no converging folds. The pathologic evaluation for the presence of ulceration was completed after surgery or ER in these cases. Ulceration was defined as a pathological fibrosis in the submucosal or deeper layer of the exact site of the lesion. Pathologic ulceration was found only in Fig. 1A, B, E, G. All of the endoscopic images used in the questionnaire were acquired from the electronic database of Incheon St. Mary's Hospital and were confirmed as differentiated adenocarcinoma histologically. This survey was approved by the Institutional Review Board of The Catholic University of Korea.

\section{Statistical analysis}

Descriptive statistics were computed for all variables. Categorical variables were compared using the $\chi^{2}$ test or Fisher's exact test. Two-sided $p$-values $<0.05$ were regarded as statistically significant. All analyses were performed using the SPSS 
for Windows version 19 (SPSS Inc., Chicago, IL, USA).

\section{RESULTS}

The questionnaires were e-mailed to 197 Korean endoscopists, practicing in Korea, and 103 doctors replied (52.3\%) without vacant answers.

\section{Demographic characteristics of the respondents}

The demographic characteristics of the respondents are summarized in Table 1. The average age of the respondents was $41.6 \pm 11.3$ years; most of the respondents were men (81.4\%), and all of them were board-certified in internal medicine. The academic staff accounted for $\sim 57 \%$ of all respondents. Sixty-four (62.1\%) respondents practiced over 5 years following board certification; 59 (57.3\%) respondents practiced over 5 years; and 59 (57.3\%) respondents experienced ESD.

\section{Diagnosis of ulceration}

The diagnostic accuracy of each image was as follows: image A, $88.3 \%$; image B, $93.2 \%$; image C, $28.2 \%$; image D, $84.5 \%$; image E, 35.9\%; image F, $83.5 \%$; and image G, $84.5 \%$.

The results of the diagnosis of ulceration for the seven endoscopic images are presented in Fig. 2. The respondents diagnosed positive ulcerations predominantly for endoscopic images A, B, C, and G. However, opposite results were revealed in endoscopic images $\mathrm{D}, \mathrm{E}$, and $\mathrm{F}$.

No significant differences were detected in the diagnosis of ulceration in each endoscopic image between the academic staff and other respondents. There were no significant dif-
Table 1. Basic Characteristics of the Respondents of This Survey

\begin{tabular}{|c|c|}
\hline & Number (\%) \\
\hline Number of respondents & 103 \\
\hline \multicolumn{2}{|l|}{ Age, yr } \\
\hline $30-39$ & $52(50.5)$ \\
\hline $40-49$ & $38(36.9)$ \\
\hline $50-59$ & $8(7.8)$ \\
\hline$\geq 60$ & $5(4.9)$ \\
\hline Male sex & $84(81.6)$ \\
\hline \multicolumn{2}{|l|}{ Medical board status } \\
\hline Internal medicine & $103(100.0)$ \\
\hline \multicolumn{2}{|l|}{ Position } \\
\hline Academic staff & $59(57.3)$ \\
\hline In-training (fellow) & $36(35.0)$ \\
\hline Hired & $8(7.8)$ \\
\hline \multicolumn{2}{|c|}{ Experience following board certification, yr } \\
\hline$<5$ & $39(37.9)$ \\
\hline$\geq 5$ & $64(62.1)$ \\
\hline \multicolumn{2}{|l|}{ Endoscopic experience, yr } \\
\hline$<5$ & $44(42.7)$ \\
\hline$\geq 5$ & $59(57.3)$ \\
\hline \multicolumn{2}{|l|}{ Experience in ESD } \\
\hline None & $44(42.7)$ \\
\hline Yes & $59(57.3)$ \\
\hline \multicolumn{2}{|c|}{ Cases of experience in ESD ${ }^{a)}$} \\
\hline$<100$ cases & $19(32.2)$ \\
\hline$\geq 100$ cases & $40(67.8)$ \\
\hline
\end{tabular}

ESD, endoscopic submucosal dissection.

a) The respondents with ESD experience of $<100$ cases are compared with those with ESD experience of $\geq 100$ cases.

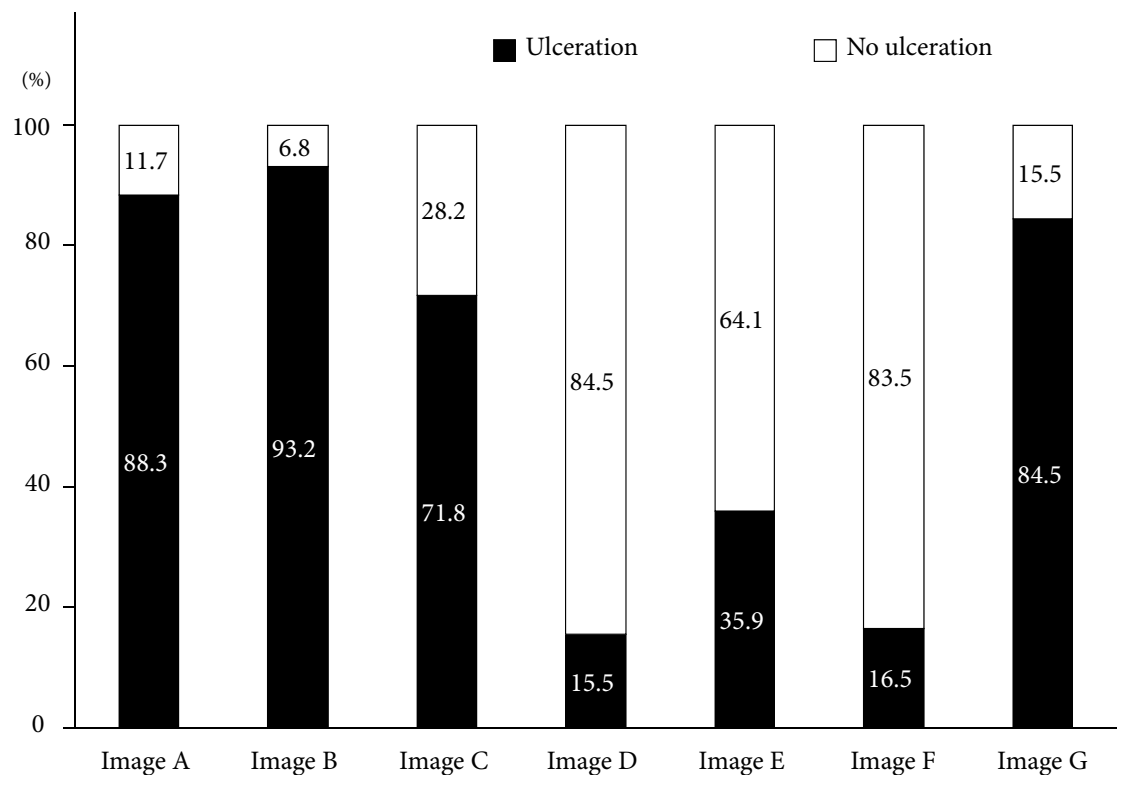

Fig. 2. Diagnostic rates of endoscopic ulceration in each endoscopic image. 


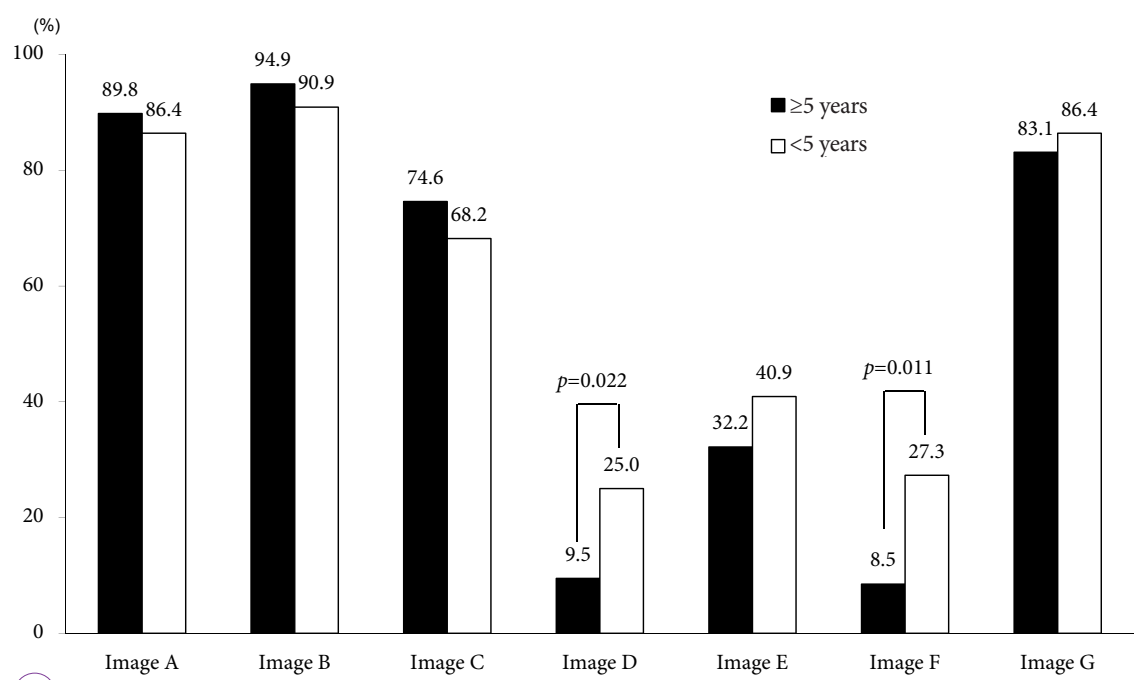

(A)

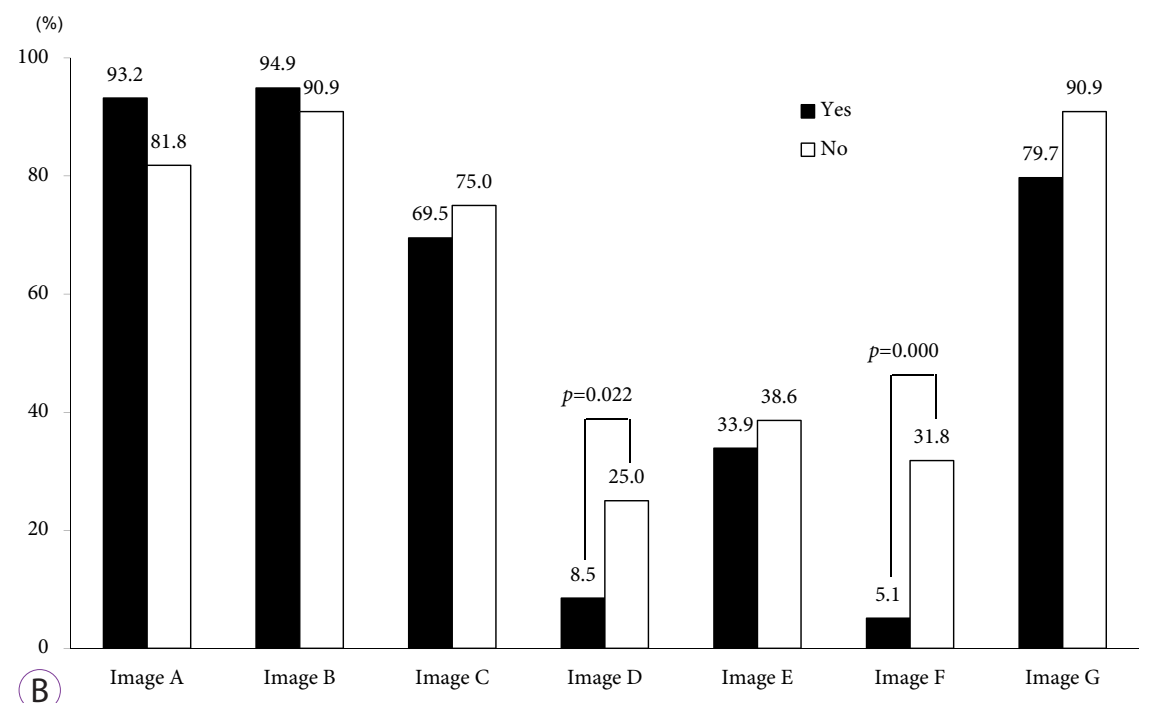

Fig. 3. Comparison of the diagnostic rates of endoscopic ulceration in each endoscopic image. (A) Endoscopic experience, $<5$ years vs. $\geq 5$ years. (B) Endoscopic submucosal dissection experience, none vs. yes.

ferences in the diagnosis of ulceration in all the endoscopic images between those with experience over 5 years following board certification and $<5$ years. There were significant differences in the diagnosis of ulceration in endoscopic images $\mathrm{D}$ and $\mathrm{F}$ between the more endoscopic experienced and the less endoscopic experienced respondents (Fig. 3A). In endoscopic images $\mathrm{D}$ and $\mathrm{F}$, the rate of the diagnosis of ulceration was significantly higher in the less endoscopic experienced respondents than in the more endoscopic experienced respondents ( $25.0 \%$ vs. $9.5 \%, p=0.022$ and $27.3 \%$ vs. $8.5 \%, p=0.011)$. There were significant differences in the diagnosis of ulceration in endoscopic images $\mathrm{D}$ and $\mathrm{F}$ between the ESD-experienced and non-ESD-experienced respondents (Fig. 3B). In endoscopic images D and F, the diagnostic rate of ulceration was significantly higher in the non-ESD-experienced respondents than in the ESD-experienced respondents ( $25.0 \%$ vs. $8.5 \%, p=0.022$ and $31.8 \%$ vs. $5.1 \%, p=0.000$ ). We additionally analyzed the effect of proficiency for ESD on the diagnosis of ulceration in the ESD-experienced respondents. There was no significant difference between the respondents who had performed ESD over 100 cases and $<100$ cases in all endoscopic images.

\section{DISCUSSION}

Since it is difficult to evaluate histologic ulcerations via biopsy specimens before treatment, the presence of ulceration must be determined during endoscopy. We found that the endoscopic definition of ulceration in EGC was quite different among the endoscopists. The differences were especially remarkable in the EGC lesions without mucosal breaks and converging folds (endoscopic images D and F), which turned 
out to have no ulceration histologically. Overestimation was higher when the endoscopists were less experienced and when they lack ESD experience. The position, level of practical experience following board certification, and level of proficiency in ESD did not affect the diagnosis of endoscopic ulceration. As a result, endoscopists with less endoscopic experience or no experience for ESD tended to overestimate endoscopic ulcerations in EGC. Those endoscopists probably had few opportunities to diagnose and manage patients with EGC ulcerations in the clinical practice. Therefore, they may recommend a more aggressive treatment, such as surgical gastrectomy, to patients with EGC without endoscopic ulcerations, who could be managed via ER. The surgical treatment for EGC has a similar long-term survival rate, but it has higher complication rates, longer hospital stays, and worse quality of life outcomes after treatment compared with endoscopic treatment. ${ }^{7-10}$ To avoid an unnecessary surgical treatment for EGC, the presence of an ulceration in EGC should be reviewed by experienced endoscopists, and training programs should be developed to diagnose endoscopic ulceration accurately.

Most of the respondents preferred to diagnose the lesions with depression or mucosal break as endoscopic ulcerations, such as in endoscopic images A, B, C, and G. However, images $\mathrm{A}, \mathrm{B}, \mathrm{E}$, and $\mathrm{G}$ turned out to have ulcerations in the final pathologic results. About two-thirds of the respondents (64.1\%) diagnosed image $\mathrm{E}$ with converging folds and without mucosal breaks as no ulceration. Endoscopic image E should be diagnosed as endoscopic ulceration because the converging folds represent scars induced by ulcerations. ${ }^{11}$ Converging folds without mucosal defect should be considered as scarring from previous ulcerations. The presence of ulcer scars negatively affects the outcomes of ER, including increased perforation risks, postoperative bleeding risk, and procedure. ${ }^{12-14}$ A proper endoscopic evaluation for ulcer scars should be conducted to decrease adverse events before ER. If an EGC lesion has converging folds, this lesion should be considered to accompany ulcer scars and it should be managed by proficient endoscopists.

The definitions of ulceration varied in the clinical trials for the prevention of nonsteroidal anti-inflammatory drug (NSAID) ulceration, depending on the diameter or the accompanied description for the depth of the lesion. ${ }^{15}$ However, most of the studies defined lesions with a diameter $\geq 3 \mathrm{~mm}$ or unequivocal depth as endoscopic ulcerations; however, the definition for endoscopic ulceration in EGC has not been established clearly. The diagnosis of ulceration seems to be related to the experience of endoscopists in performing ESD. Therefore, an establishment of definite diagnostic criteria for endoscopic ulcerations in EGC may be needed to decrease the differences among endoscopists. Further, endoscopists should check the final pathology report of ESD specimens for the presence of ulcerations, which can improve their insight into the diagnosis of ulcerations during endoscopy.

This survey had several limitations. First, there were no respondents who worked in primary medical centers in this survey. Most patients with EGC are diagnosed in primary medical centers and referred to gastroenterologists or surgeons of tertiary referral centers in Korea. The opinion of the endoscopists in primary medical centers for endoscopic ulcerations with EGC is important, since their diagnosis for endoscopic ulcerations can determine the treatment methods. Further surveys including endoscopists from primary medical centers are anticipated. Second, there could be a non-response bias in this survey. The response rates were $18 \%$ and $11.3 \%$ in two other surveys targeting endoscopists, ${ }^{16,17}$ which were lower than the response rate (52.3\%) in this survey. Such a higher response rate would decrease the non-response bias in this survey.

In conclusion, this survey found that endoscopic ulcerations in EGC are quite difficult to define, especially for endoscopists with less endoscopic experience or no experience in ESD. Since an overestimation may result in a more aggressive treatment, such as gastrectomy in EGC, the presence of ulcerations in EGC should be reviewed by experienced endoscopists, and educational programs for less experienced endoscopists should be developed.

\section{Conflicts of Interest}

The authors have no financial conflicts of interest.

\section{REFERENCES}

1. Carter KJ, Schaffer HA, Ritchie WP Jr. Early gastric cancer. Ann Surg 1984;199:604-609.

2. Everett SM, Axon AT. Early gastric cancer in Europe. Gut 1997;41:142150 .

3. Chung IK, Lee JH, Lee SH, et al. Therapeutic outcomes in 1000 cases of endoscopic submucosal dissection for early gastric neoplasms: Korean ESD study group multicenter study. Gastrointest Endosc 2009;69:12281235.

4. Isomoto H, Shikuwa S, Yamaguchi N, et al. Endoscopic submucosal dissection for early gastric cancer: a large-scale feasibility study. Gut 2009;58:331-336.

5. Gotoda T, Yanagisawa A, Sasako M, et al. Incidence of lymph node metastasis from early gastric cancer: estimation with a large number of cases at two large centers. Gastric Cancer 2000;3:219-225.

6. Japanese Gastric Cancer Association. Japanese gastric cancer treatment guidelines 2010 (ver. 3). Gastric Cancer 2011;14:113-123.

7. Kim DY, Hong SJ, Cho GS, et al. Long-term efficacy of endoscopic submucosal dissection compared with surgery for early gastric cancer: a retrospective cohort study. Gut Liver 2014;8:519-525.

8. Chiu PW, Teoh AY, To KF, et al. Endoscopic submucosal dissection (ESD) compared with gastrectomy for treatment of early gastric neoplasia: a retrospective cohort study. Surg Endosc 2012;26:3584-3591.

9. Park CH, Lee H, Kim DW, et al. Clinical safety of endoscopic submu- 
cosal dissection compared with surgery in elderly patients with early gastric cancer: a propensity-matched analysis. Gastrointest Endosc 2014;80:599-609.

10. Choi JH, Kim ES, Lee YJ, et al. Comparison of quality of life and worry of cancer recurrence between endoscopic and surgical treatment for early gastric cancer. Gastrointest Endosc 2015;82:299-307.

11. Sakita T, Oguro Y, Takasu S, Fukutomi H, Miwa T. Observations on the healing of ulcerations in early gastric cancer. The life cycle of the malignant ulcer. Gastroenterology 1971;60:835-839.

12. Ojima T, Takifuji K, Nakamura M, et al. Complications of endoscopic submucosal dissection for gastric noninvasive neoplasia: an analysis of 647 lesions. Surg Laparosc Endosc Percutan Tech 2014;24:370-374.

13. Miyahara K, Iwakiri R, Shimoda R, et al. Perforation and postopera- tive bleeding of endoscopic submucosal dissection in gastric tumors: analysis of 1190 lesions in low- and high-volume centers in Saga, Japan. Digestion 2012;86:273-280.

14. Imagawa A, Okada H, Kawahara Y, et al. Endoscopic submucosal dissection for early gastric cancer: results and degrees of technical difficulty as well as success. Endoscopy 2006;38:987-990.

15. Yeomans ND, Naesdal J. Systematic review: ulcer definition in NSAID ulcer prevention trials. Aliment Pharmacol Ther 2008;27:465-472.

16. Faulx AL, Vela S, Das A, et al. The changing landscape of practice patterns regarding unsedated endoscopy and propofol use: a national Web survey. Gastrointest Endosc 2005;62:9-15.

17. Yusuf TE, Harewood GC, Clain JE, Levy MJ. International survey of knowledge of indications for EUS. Gastrointest Endosc 2006;63:107-111. 